MATEC Web of Conferences 33, 06006 (2015)

DOI: $10.1051 /$ matecconf/ 20153306006

(C) Owned by the authors, published by EDP Sciences, 2015

\title{
Electronic and crystal structure of the high entropy TiZrHfCoNiCu intermetallics undergoing martensitic transformation
}

\author{
Georgiy Firstov $^{\mathrm{a}}$, Andrei Timoshevski, Tetiana Kosorukova, Yuri Koval, Yuri Matviychuk, Pavlo Verhovlyuk \\ G.V. Kurdyumov Institute for Metal Physics of the National Academy of Sciences of Ukraine, 36 Vernadsky blvd., Kiev 03680, Ukraine
}

\begin{abstract}
It was shown very recently that despite high thermal stability some high entropy alloys, namely, intermetallic compounds of TiZrHfCoNiCu family, undergo martensitic transformation and exhibit shape memory effect [1]. It was also found that X-ray diffraction patterns taken from those compounds resemble qualitatively ones of B2 ordering type for austenitic state and B19' - for martensite. It is going to be shown [2] that the ordered structure of austenite phase is not B2 but is a result of group-subgroup transition down to triclinic P1 space group. Present paper reports onto the results of electron structure modelling combined with crystal structure analysis with the help of experimental data Rietveld refinement performed for TiZrHfCoNiCu intermetallics. Crystal structures of austenite and martensite phases for these high entropy intermetallics will be discussed.
\end{abstract}

\section{Introduction}

Recently, the concept of the novel structural materials high entropy alloys (HEA) has been introduced [3]. Very recently, following HEA concept mentioned above, it was found that HEA of TiZrHfCoNiCu intermetallic family might undergo martensitic transformation (MT), which is accompanied by shape memory effect with attractive parameters [1], including MT and shape memory temperatures above $400 \mathrm{~K}$. The latter, according to $[4,5]$, allows to consider these high entropy intermetallic compounds as perspective functional materials - high temperature shape memory alloys.

The crystal structure of the stable high temperature phase of TiZrHfCoNiCu high entropy intermetallic can be considered roughly as of B2 type [1]. It was also shown that B2 phase becomes unstable to MT on cooling in this high entropy intermetallic, once Co is replaced equally by $\mathrm{Cu}$ and $\mathrm{Ni}$. The scheme of the MT in this case might be considered as B2 $\leftrightarrow \mathrm{B} 19^{`}$. The aim of the present paper is to find a physical reason for martensitic instability of TiZrHfCoNiCu high entropy intermetallics through study of their crystal and electronic structure.

\section{Experimental and calculation details}

The alloys for the present investigation were prepared from iodideTi, $\mathrm{Zr}$ and $\mathrm{Hf}$ and electrolytic $\mathrm{Cu}, \mathrm{Ni}$ and $\mathrm{Co}$ by arc melting under an atmosphere of purified argon. The weight of the ingots was typically $1-5 \mathrm{~g}$. The pellets were turned over and remelted several times in order to ensure good homogeneity. The crystal structure of the samples was analyzed by X-ray powder diffraction
(XRD), using a Bruker AXS D8 Advance diffractometer with $\quad \theta-2 \theta \quad$ Bragg-Brentano geometry and monochromatized $\mathrm{Cu} \mathrm{K \alpha} 1$ radiation $(\lambda=1.5406 \AA)$. MAUD software [6] was used for Rietveld refinement. MT temperatures were detected with the help of DSC (Netzsch 404 F1). Electronic and crystal structure calculations were performed for ordered structure, modelling equiatomic TiZrHfCoNiCu high entropy intermetallic. These calculations were carried out using FLAPW method implemented in Wien $2 \mathrm{k}$ software package [7]. High precision of the FLAPW method allows to perform optimization of the lattice parameters and atomic coordinates in the unit cell (accuracy of the forces calculation - $3 \mathrm{mRy} / \mathrm{a} . u$.). Atomic sphere radii were 2.2 a.u. for $\mathrm{Ti}$ and $\mathrm{Zr}, 2.5$ a.u. for $\mathrm{Hf}, 2.1$ a.u. for $\mathrm{Co}, \mathrm{Ni}$ and $\mathrm{Cu}$. The calculations were fulfilled for $63 \mathrm{k}$ points in the irreducible part of the first Brillouin zone (BZ) that corresponded to $200 \mathrm{k}$-points in the whole BZ. Inside the atomic spheres the wave function was expanded up to $1_{\max }=12$. The electronic density and potential inside the spheres were expanded on the lattice harmonics basis up to $\mathrm{L}_{\max }=6$. The $\mathrm{R}_{\min } \mathrm{K}_{\max }$ parameter, which controls the number of APW functions in the basic set, was 9.125 that corresponded to $\sim 160 \mathrm{APW}$ per atom. The $\mathrm{G}_{\max }$ value, determining the number of plane waves in the inter-sphere potential expansion, was equal to 12 . These parameters allowed to calculate the total energy of the model ordered structure with accuracy of $0.001 \mathrm{eV}$.

\section{Results and discussion}

The results of [1] made it clear that ratio of Co against $\mathrm{Ni}$ and $\mathrm{Cu}$ composition in $(\mathrm{TiZrHf})_{50}(\mathrm{CoNiCu})_{50}$ high entropy intermetallics is crucial in a sense of martensitic

\footnotetext{
a Corresponding author: gfirst@imp.kiev.ua, yuri.firstov@gmail.com
} 
instability, which Co definitely suppressed. In order to clarify the influence of this ratio, we varied $\mathrm{Co}, \mathrm{Ni}$ and $\mathrm{Cu}$ composition, while controlling the MT in these compounds through calorimetric and structural measurements. Fig. 1 shows the X-ray diffraction patterns taken from $(\mathrm{TiZrHf})_{50}(\mathrm{CoNiCu})_{50}$ compounds, containing different amount of $\mathrm{Co}, \mathrm{Ni}, \mathrm{Cu}$ and showing signs of $\left(\mathrm{B} 2+\mathrm{B} 19^{\prime}\right)$ phase mixture, analogously to (TiZrHf) ${ }_{50} \mathrm{Ni}_{25} \mathrm{Cu}_{25}$ high entropy intermetallic studied in [1].

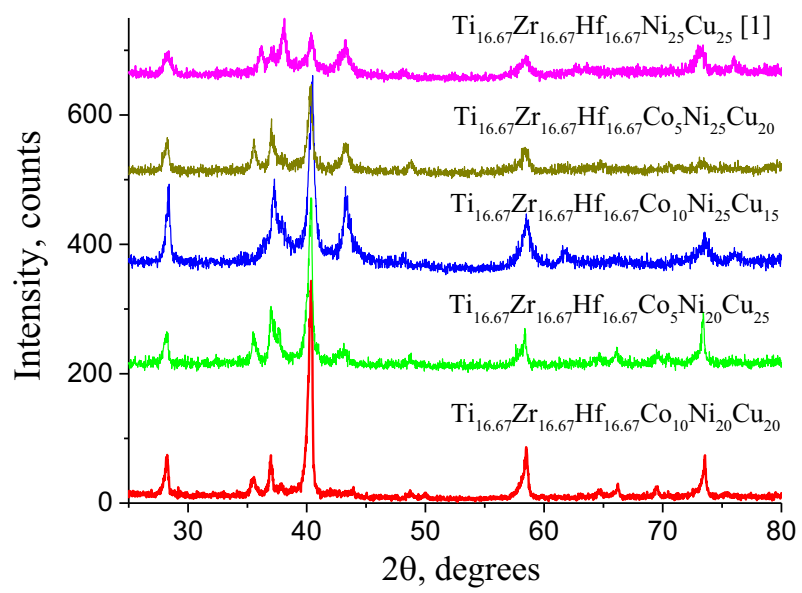

Figure 1. Comparison of the X-ray diffraction patterns taken from $(\mathrm{TiZrHf})_{50}(\mathrm{CoNiCu})_{50}$ compounds at normal conditions and containing different amount of $\mathrm{Co}, \mathrm{Ni}$ and $\mathrm{Cu}$.

X-ray data shown in Fig. 1 were subjected to Rietveld refinement, using the assumption of (B2+B19') phase mixture. In Table 1 the resulting lattice parameters for B2 and B19' phases, their volume per atom (V/at) values against starting temperature of the forward MT (Ms) are shown for $(\mathrm{TiZrHf})_{50}(\mathrm{CoNiCu})_{50}$ compounds, containing different amount of $\mathrm{Co}, \mathrm{Ni}$ and $\mathrm{Cu}(\mathrm{Ti}, \mathrm{Zr}$ and $\mathrm{Hf}$ are in equal amount for all compositions studied - 16.667 at.\%).

Table 1. Crystal structure parameters for B2, B19` martensites and $\mathrm{Ms}$ for $(\mathrm{TiZrHf})_{50}(\mathrm{CoNiCu})_{50}$ compounds, containing different amount of $\mathrm{Co}, \mathrm{Ni}$ and $\mathrm{Cu}$.

\begin{tabular}{|c|c|c|c|c|c|c|c|}
\hline \multirow{2}{*}{$\begin{array}{c}\mathrm{Co}+\mathrm{Ni}+\mathrm{Cu}, \\
\text { at. } \%\end{array}$} & \multirow{2}{*}{$\begin{array}{c}\text { Ms, } \\
\mathrm{K}\end{array}$} & \multirow{2}{*}{ Phase } & $\mathbf{a}$ & b & c & \multirow{2}{*}{$\beta,{ }^{\circ}$} & \multirow{2}{*}{ V/at, $\AA^{3}$} \\
\hline & & & \multicolumn{3}{|c|}{$\AA ̊$} & & \\
\hline \multirow{2}{*}{$\mathrm{Co}_{0} \mathrm{Ni}_{25} \mathrm{Cu}_{25}$} & \multirow{2}{*}{500} & B2 & 3.167 & - & - & 90 & 15.891 \\
\hline & & B19 & 3.155 & 4.168 & 4.967 & 100.9 & 16.032 \\
\hline \multirow{2}{*}{$\mathrm{Co}_{5} \mathrm{Ni}_{25} \mathrm{Cu}_{20}$} & \multirow{2}{*}{454} & B2 & 3.162 & - & - & 90 & 15.810 \\
\hline & & B19 & 3.158 & 4.312 & 4.847 & 99.9 & 16.254 \\
\hline \multirow{2}{*}{$\mathrm{Co}_{10} \mathrm{Ni}_{25} \mathrm{Cu}_{15}$} & \multirow{2}{*}{430} & B2 & 3.154 & - & - & 90 & 15.686 \\
\hline & & B19 & 3.106 & 4.180 & 4.938 & 102.6 & 15.646 \\
\hline \multirow{2}{*}{$\mathrm{Co}_{5} \mathrm{Ni}_{20} \mathrm{Cu}_{25}$} & \multirow{2}{*}{376} & B2 & 3.152 & - & - & 90 & 15.653 \\
\hline & & $\mathrm{B} 19^{\circ}$ & 3.130 & 4.317 & 4.853 & 99.5 & 16.167 \\
\hline \multirow{2}{*}{$\mathrm{Co}_{10} \mathrm{Ni}_{20} \mathrm{Cu}_{20}$} & \multirow{2}{*}{260} & $\mathrm{~B} 2$ & 3.161 & - & - & 90 & 16.126 \\
\hline & & B19 & 3.179 & 4.254 & 4.845 & 100.1 & 15.799 \\
\hline
\end{tabular}

It can be seen (Table 1) that Ms temperature varies in the wide temperature range from 260 to $500 \mathrm{~K}$. Co additions indeed strongly suppress MT. The strongest is the effect of $\mathrm{Ni}$ substitution by $\mathrm{Co}$, as the rate of $\mathrm{Ms}$ decrease is $-25 \mathrm{~K} / \mathrm{at} . \%$ of $\mathrm{Co}$. The effect of $\mathrm{Cu}$ substitution is much less pronounced (rate of Ms decrease is $-7 \mathrm{~K} / \mathrm{at} . \%$ of $\mathrm{Co}$ ), while mutual substitution of $\mathrm{Ni}$ and
$\mathrm{Cu}$ by $\mathrm{Co}$ is almost the same for $\mathrm{Ni}$ substitution only rate of Ms decrease is $-24 \mathrm{~K} / \mathrm{at} . \%$ of Co.

An interesting dependence (built upon the data from Table 1) of volume per atom upon Ms temperature for B2 and B19' phases is given in Fig. 2.

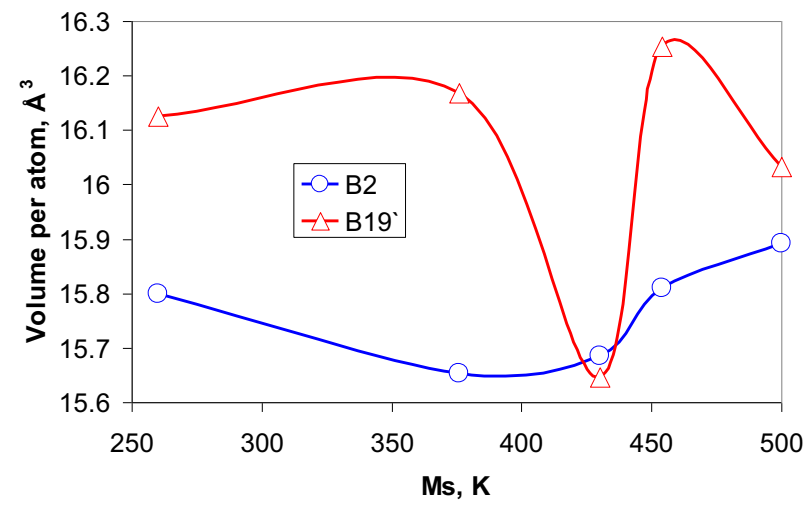

Figure 2. Volume per atom for B2 and B19` phases against Ms for $(\mathrm{TiZrHf})_{50}(\mathrm{CoNiCu})_{50}$ compounds, undergoing MT.

Both dependencies shown in Fig. 2 are nonmonotonous. Starting from the lowest Ms temperature (most stable B2 phase amongst considered), volume per atom of B2 phase begins to decrease, passes through a minimum around $400 \mathrm{~K}$ and increases up to $15.891 \AA^{3}$ at Ms of $500 \mathrm{~K}$ for (TiZrHf) ${ }_{50} \mathrm{Ni}_{25} \mathrm{Cu}_{25}$ high entropy intermetallic (Table 1). In other words, the strongest interatomic interaction (smallest volume per atom) is not characteristic for the most stable B2 phase. B19 volume per atom is much bigger than B2 and tends to grow with Ms except for the minimum that corresponds to the minimum of B2 dependence and for the composition without Co with highest Ms (most stable B19` phase amongst considered). Moreover, in the case of $\mathrm{Ti}_{16.667} \mathrm{Zr}_{16.667} \mathrm{Hf}_{16.667} \mathrm{Co}_{10} \mathrm{Ni}_{25} \mathrm{Cu}_{15}$ high entropy intermetallic, the volume of B19' martensite is smaller than the volume of B2 austenite. It means that the volume change during forward MT in this compound has a negative sign similar to TiNi (see [8] for example) and contrary to all high temperature shape memory alloys [9], including high entropy intermetallics under consideration (Table 1, Fig. 2).

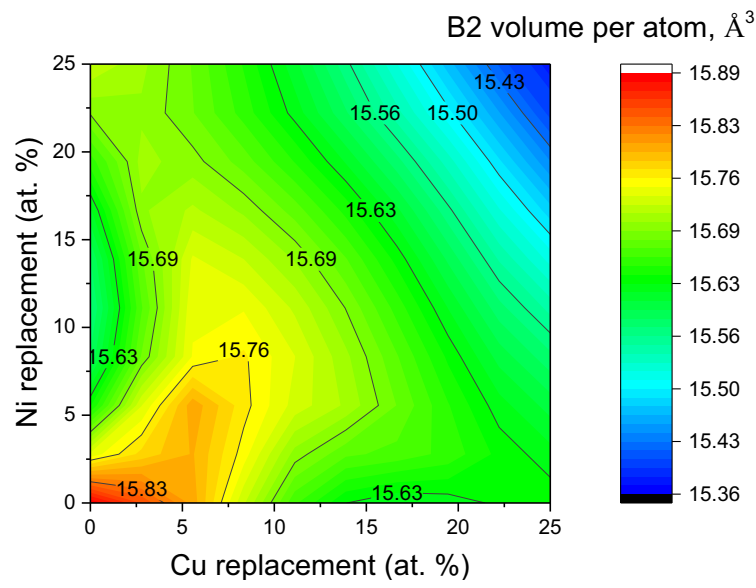

Figure 3. Contour map for $\mathrm{B} 2$ volume per atom versus $\mathrm{Co}$ additions instead of $\mathrm{Ni}$ and $\mathrm{Cu}$ for $(\mathrm{TiZrHf})_{50}(\mathrm{CoNiCu})_{50}$ alloys. 
In Fig. 3 the volume per atom for B2 phase contour map dependence upon $\mathrm{Co}$ additions instead of $\mathrm{Ni}$ and $\mathrm{Cu}$ was built with the help of OriginPro 2015 software package (Renka Cline gridding method) using the data from Table 1, reference [1] and volume per atom for $(\mathrm{TiZrHf})_{50} \mathrm{Co}_{50}$ B2 compound with lattice parameter $\mathrm{a}_{\mathrm{B} 2}=3.133_{3} \AA$. All HEA compositions in Fig. 3 are located within the circle with 25 at.\% radius, which connects compositions $\mathrm{Ti}_{16.667} \mathrm{Zr}_{16.667} \mathrm{Hf}_{16.667} \mathrm{Co}_{25} \mathrm{Cu}_{25}$ and $\mathrm{Ti}_{16.667} \mathrm{Zr}_{16.667} \mathrm{Hf}_{16.667} \mathrm{Co}_{25} \mathrm{Ni}_{25}\left(\Delta \mathrm{S}_{\text {mix }}=13.2119 \mathrm{JK}^{-1} \mathrm{~mol}^{-1}\right)$. It can be seen that, while Co replaces $\mathrm{Ni}$, interatomic distances are declining almost as it could be seen for $\mathrm{Cu}$ replacement. At first (up to 2 at.\% for Ni and 5 at.\% for $\mathrm{Cu}$ replacement), the decline is slow but accelerates then and volume per atom arrives at almost the same value at 15 at.\% of $\mathrm{Co}$ in both cases - $15.6 \AA^{3}$. Mutual replacement of $\mathrm{Ni}$ and $\mathrm{Cu}$ by $\mathrm{Co}$ is accompanied by much slower decline in volume per atom, which passes through the retardation up to 10 at.\%, and being still in the HEA region, at $\mathrm{Ti}_{16.667} \mathrm{Zr}_{16.667} \mathrm{Hf}_{16.667} \mathrm{Co}_{16.667} \mathrm{Ni}_{16.667} \mathrm{Cu}_{16.667}$ equiatomic composition $\left(\Delta \mathrm{S}_{\text {mix }}=14.8975 \mathrm{JK}^{-1} \mathrm{~mol}^{-1}\right)$, it still has the value of about $15.7 \AA^{3}$. Generally, it means that the introduction of $\mathrm{Co}$ atoms instead of $\mathrm{Ni}$ or $\mathrm{Cu}$ induces stronger interatomic interaction, comparing with mutual $\mathrm{Ni}$ and $\mathrm{Cu}$ substitution by Co. Of course, we can not speculate more about interatomic interaction in these materials, while still using B2 phase for the description of HEA X-ray patterns, as it suggests chaotic distribution of atoms at $1 \mathrm{a}$ and $1 \mathrm{~b}$ Wyckoff positions in this ordered bcc structure. It is impossible to distribute evenly 6 types of atoms in this structure and, therefore, this fact becomes an obstacle for any ab-initio modelling of electron and crystal structure. Fig. 4 shows B2 related HEA structure variant, which became a solution for such problem.

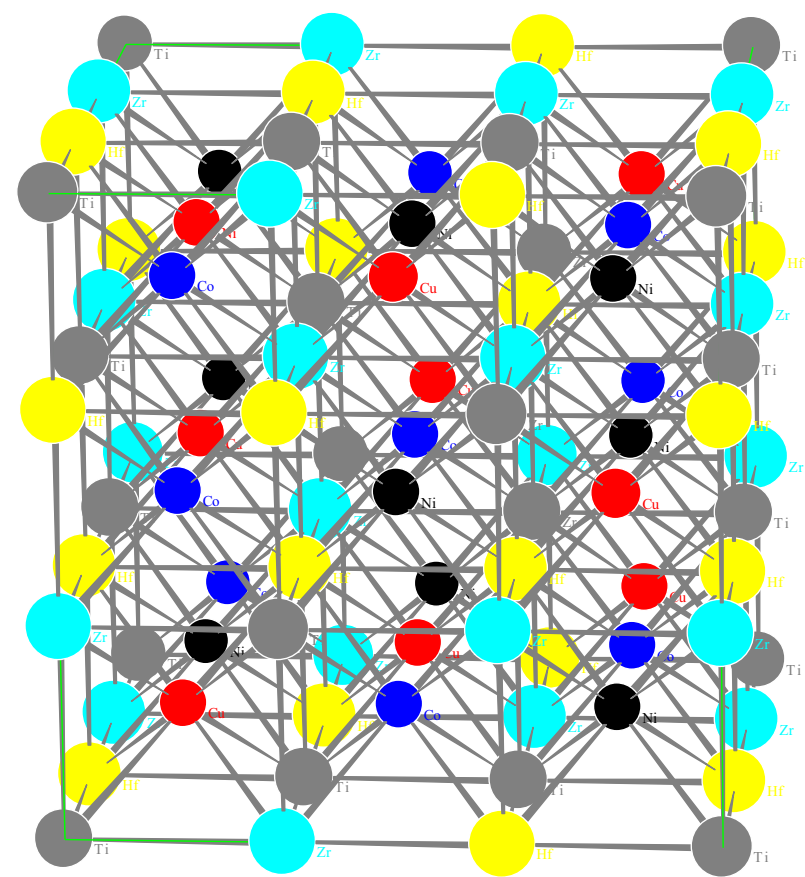

Figure 4. Triclinic (P1, No 1) unit cell of TiZrHfCoNiCu HEA $\left(\mathrm{a}_{\mathrm{P} 1}=\mathrm{b}_{\mathrm{P} 1}=\mathrm{c}_{\mathrm{P} 1}=9.477 \AA\right.$ and $\left.\alpha_{\mathrm{P} 1}=\beta_{\mathrm{P} 1}=\gamma_{\mathrm{P} 1}=90^{\circ}\right)$ derived from B2 (Pm3m, No 221) unit cell $\left(\mathrm{a}_{\mathrm{B} 2}=3.159 \AA\right)$ through the following group-subgroup transition path: No 221 (Pm3m; 2 atoms) $\rightarrow$ $221(54$ atoms $) \rightarrow 207 \rightarrow 195 \rightarrow 16 \rightarrow 3 \rightarrow$ No $1(\mathrm{P} 1)[2]$.
So, it should be noted that our further investigations has shown already that in fact we are dealing not with a B2 but with a very distorted structure, which only resembles B2 qualitatively, does not fit properly into Rietveld refinement and ought to be described as belonging to $\mathrm{P} 1$ triclinic space group due to certain peculiarities in electronic and crystal structure [2] (the same has to be true also for the structure we denoted here as B19'). Arrival at this triclinic space group from Pm3m was done through series of group-subgroup transitions for the structure, modelling equiatomic TiZrHfCoNiCu compound. As a result, the unit cell was obtained, consisting of 54 atoms, where atoms of all 6 constituents of this high entropy intermetallic occupy nine 1a Wyckoff positions each, as it can be seen in Fig. 4 .

$\mathrm{Ab}$-initio modelling of the crystal and electronic structure of the equiatomic TiZrHfCoNiCu compound was carried out with the help of this $\mathrm{Ti}_{9} \mathrm{Zr}_{9} \mathrm{Hf}_{9} \mathrm{Co}_{9} \mathrm{Ni}_{9} \mathrm{Cu}_{9}$ model structure, where all triclinic angles were kept at $90^{\circ}$ and $\mathrm{a}_{\mathrm{P} 1}=\mathrm{b}_{\mathrm{P} 1}=\mathrm{c}_{\mathrm{P} 1}$ for the unit cell to simplify the calculations. As a result, atomic coordinates and lattice parameters were optimized. Optimized lattice parameters $\mathrm{a}_{\mathrm{P} 1}=\mathrm{b}_{\mathrm{P} 1}=\mathrm{c}_{\mathrm{P} 1}=9.466 \AA$ are smaller than the starting value $9.477 \AA$ (Fig. 4). Each $\mathrm{Co}, \mathrm{Ni}$ and $\mathrm{Cu}$ atom in their initial ideal positions has 8 nearest neighbours (Ti, Zr, Hf) at the distance of $2.73 \AA$ and 6 neighbours in the second coordination sphere $(\mathrm{Co}, \mathrm{Ni}, \mathrm{Cu})$ at the distance of 3.16 A. Calculations have shown that all atoms shifted from their ideal positions significantly that lead to the strong changes in the interatomic distances of the model structure. These calculation results are shown in Fig. 5.

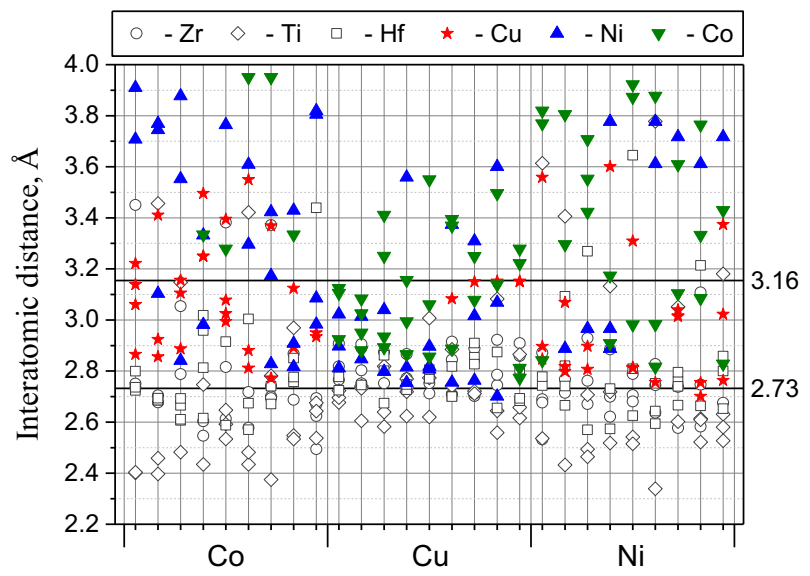

Figure 5. Calculated interatomic distances of $\mathrm{A}-\mathrm{B}$ and $\mathrm{B}-\mathrm{B}(\mathrm{A}=$ $\mathrm{Ti}, \mathrm{Zr}, \mathrm{Hf} ; \mathrm{B}=\mathrm{Co}, \mathrm{Ni}, \mathrm{Cu}$ ) types in the model $\mathrm{Ti}_{9} \mathrm{Zr}_{9} \mathrm{Hf}_{9} \mathrm{Co}_{9} \mathrm{Ni}_{9} \mathrm{Cu}_{9}$ structure. Interatomic distances in the ideal structure prior to optimization $\mathrm{A}-\mathrm{B}=2.73 \AA$ and $\mathrm{B}-\mathrm{B}=3.16 \AA$ are also shown.

Bond lengths for all $\mathrm{Co}, \mathrm{Cu}$ and $\mathrm{Ni}$ atoms are shown in Fig. 5. It can be seen that the bond lengths between $\mathrm{Cu}$ and $\mathrm{Ti}, \mathrm{Zr}$ and $\mathrm{Hf}$ atoms are close to ideal ones but bond lengths between $\mathrm{Co}, \mathrm{Ni}$ and $\mathrm{Ti}, \mathrm{Zr}$, $\mathrm{Hf}$ atoms are significantly smaller than in ideal $(2.73 \AA)$ case. It should be also noted that interatomic distances between $\mathrm{Cu}, \mathrm{Ni}$ and other $\mathrm{Co}, \mathrm{Cu}$ and $\mathrm{Ni}$ atoms are significantly smaller than ideal ones also. In other words, it means that some $\mathrm{Cu}$ and $\mathrm{Ni}$ atoms are entering the first coordination sphere for other $\mathrm{Ni}$ and $\mathrm{Cu}$ atoms. Co interacts in a strongest manner with $\mathrm{A}$ atoms $(\mathrm{A}=\mathrm{Ti}, \mathrm{Zr}, \mathrm{Hf})$ but $\mathrm{Cu}$ 
atoms are the closest to Co ones amongst the atoms of $\mathrm{B}$ type $(\mathrm{B}=\mathrm{Cu}, \mathrm{Ni}, \mathrm{Co})$ as it can be seen from Fig. 5. So, it might help to explain why $\mathrm{Ni}$ replacement by $\mathrm{Co}$ is accompanied by stronger densification of the structure and more intensive decrease in Ms that can be seen in Table 1, Fig. 2 and 3. While Co atoms replace Ni ones, $\mathrm{Co}-\mathrm{Cu}$ and $\mathrm{Co}-(\mathrm{Ti}, \mathrm{Zr}, \mathrm{Hf})$ interaction increase in a manner that bond length distribution in Fig. 5 suggests. That will definitely stabilize high temperature austenitic phase against MT and the volume per atom will decrease. As for the $\mathrm{Cu}$ replacement and mutual replacement of $\mathrm{Cu}$ and $\mathrm{Ni}$ by $\mathrm{Co}$ effects onto MT, further more peculiar experimental and modelling studies are needed that will employ not the B2 and B19' crystal structures but the approach that will employ triclinically distorted B2 austenite phase ([2], Fig. 4) and, consequently, much needed triclinic model of distorted B19` martensite phase.

All the crystal structure changes, comparing with ideal model structure, presented in Fig. 5, are the direct consequence of electronic structure shown in Fig. 6.

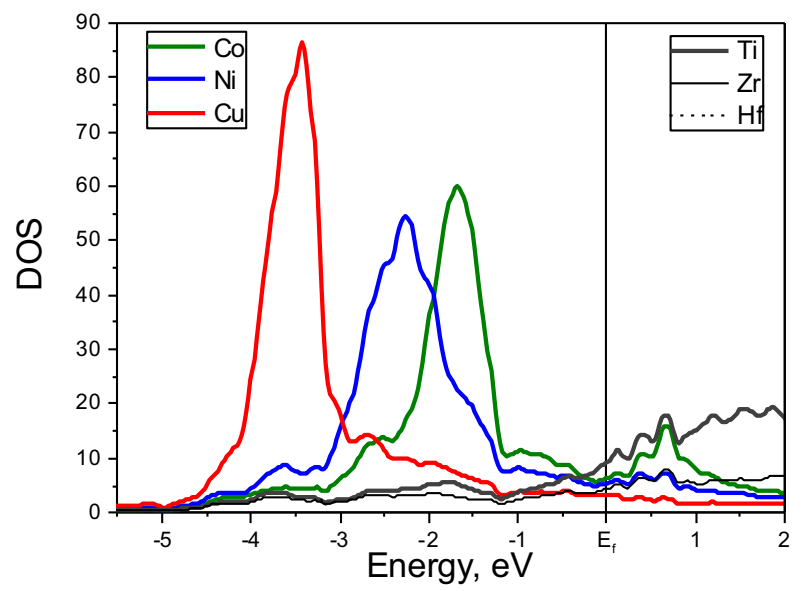

Figure 6. Local densities of electronic states (DOS) of atoms in the model $\mathrm{Ti}_{9} \mathrm{Zr}_{9} \mathrm{Hf}_{9} \mathrm{Co}_{9} \mathrm{Ni}_{9} \mathrm{Cu}_{9}$ structure.

It is visible that the occupied part of the density of electronic states (DOS) is formed by d-zones of $\mathrm{Cu}, \mathrm{Ni}$ and $\mathrm{Co}$ atoms. Non-occupied states are caused by $\mathrm{Ti}, \mathrm{Zr}$ and $\mathrm{Hf}$ atoms. Electronic structure analysis has shown that $\mathrm{d}$-states of $\mathrm{Cu}$ and $\mathrm{Ni}$ are hybridized stronger than $\mathrm{Cu}$ and Co ones. This is due to the fact that DOS peaks of $\mathrm{Cu}$ and $\mathrm{Ni}$ are close. Electronic states of $\mathrm{Co}$ are more hybridized with the electronic states of $\mathrm{Ti}, \mathrm{Zr}$ and $\mathrm{Hf}$ atoms, comparing with $\mathrm{Cu}$ and $\mathrm{Ni}$ atoms. Hybridization effects are the reason for the formation of interatomic bond lengths in the model structure, that were described above. Thus, modelling results (Fig. 5,6) allow us to conclude that $\mathrm{Co}$ atoms in high entropy intermetallics of TiZrHfCoNiCu family promote the stabilization of high temperature austenitic triclinically distorted B2 phase, while $\mathrm{Cu}$ and $\mathrm{Ni}$ atoms lead to its structural instability, which qualitatively is definitely in agreement with experimental findings (Table 1, Fig. 2).

In fact, the modelling and experimental results obtained remind very much the findings related to the origin of $\mathrm{MT}$ in $\mathrm{ZrCu}$ [10]. There, the origin of the austenitic phase instability was found in the possibility of the existence of two types of the short range order. First short range order type is determined by $\mathrm{Cu}-\mathrm{Zr}$ interaction, while the second by $\mathrm{Cu}-\mathrm{Cu}$ one. Later, absolutely the same situation was noticed for TiNi intermetallic compound [9]. In both cases, $\mathrm{Cu}-\mathrm{Zr}$ or $\mathrm{Ni}-\mathrm{Ti}$ interatomic interaction stabilizes high temperature B2 phase, while $\mathrm{Cu}-\mathrm{Cu}$ or $\mathrm{Ni}-\mathrm{Ni}$ ones appear in the martensitic phases. It was clearly seen for martensitic crystal structures by the appearance of $\mathrm{Cu}(\mathrm{Ni})$ atoms in the first coordination sphere of the atoms of their own sort $[9,10]$.

In the present case of $(\mathrm{TiZrHf})_{50}(\mathrm{CoNiCu})_{50}$ high entropy intermetallic compound, the same effect of the appearance of $\mathrm{Cu}$ and $\mathrm{Ni}$ atoms in the first coordination sphere of the atoms of their own sort is clearly visible in the high temperature austenitic phase (Fig. 5). It shows that the parent phase crystal structure is distorted already in such a way that it seems even better prepared for the possible MT than binary $\mathrm{ZrCu}$ or TiNi intermetallic compounds because their austenitic structures are dominated by only one sort of interatomic interaction. Such distortions in the crystal structure of high entropy intermetallic compound are possible due to much more degrees of freedom given by the multi-element composition.

On top of the experimental and modelling results, it can be concluded that in the high entropy TiZrHfCoNiCu intermetallic compounds two types of interatomic interaction of $\mathrm{A}-\mathrm{B}$ and $\mathrm{B}-\mathrm{B}$ type $(\mathrm{A}=\mathrm{Ti}, \mathrm{Zr}, \mathrm{Hf}$; $\mathrm{B}=\mathrm{Co}, \mathrm{Ni}, \mathrm{Cu})$ can be considered in general as the reason for the structural instability towards martensitic transformation.

\section{References}

1. G.S. Firstov, T.A. Kosorukova, Yu.N. Koval, V.V. Odnosum, Mater. Today: Proceedings, to be published (2015).

2. G.S. Firstov, A.N. Timoshevski, T.A. Kosorukova, Yu.N. Koval, Yu.V. Matviychuk, to be published.

3. B.S. Murty, Jien-Wei Yeh, S. Ranganathan, High Entropy Alloys, Elsevier Science \& Technology Butterworth-Heinemann Ltd, Oxford (2014).

4. G.S. Firstov, J. Van Humbeeck, Yu.N. Koval, J. Intell. Mat. Sys. and Struct., 17, 1041, (2006).

5. J. Ma, I. Karaman, R. D. Noebe, Int. Mat. Rev. 55, 257 (2010).

6. http://www.ing.unitn.it/ $\sim \operatorname{maud} /$.

7. P. Blaha, K. Schwarz, G.K.H. Madsen, D. Kvasnicka and J. Luitz, WIEN2K, An Augmented Plane Wave + Local Orbital's Program for Calculating Crystal Properties, ed. Karlheinz Schwarz, Technische Universität Wien, Austria (2001).

8. K. Otsuka, X. Ren, Progress in Materials Science, 50, 511 (2005).

9. G.S. Firstov, Yu.N. Koval, J. Van Humbeeck, A.N. Timoshevskii, T.A. Kosorukova, P.A. Verhovlyuk, in Shape Memory Alloys: Properties, Technologies, Opportunities, ed. N. Resnina and V. Rubanik, Trans Tech Publications Inc., Zurich, 207 (2015).

10. G. Firstov, A. Timoshevski, Yu. Koval, S. Yablonovski, J. Van Humbeeck, Materials Science Forum, 738-739, 15 (2013). 